\title{
Design of a Compact UWB Antenna with Triple Notched Bands Using Nonuniform Width Slots
}

\author{
Xu Chen, Feng Xu, and Xu Tan \\ School of Software Engineering, Shenzhen Institute of Information Technology, Shenzhen, China \\ Correspondence should be addressed to Xu Chen; chen_xu@sziit.edu.cn
}

Received 30 September 2016; Accepted 21 December 2016; Published 24 January 2017

Academic Editor: Chao Wang

Copyright (C) $2017 \mathrm{Xu}$ Chen et al. This is an open access article distributed under the Creative Commons Attribution License, which permits unrestricted use, distribution, and reproduction in any medium, provided the original work is properly cited.

\begin{abstract}
A compact printed UWB antenna with triple band-notched characteristics is proposed. Instead of conventional uniform width slots, two pairs of quarter-wavelength length nonuniform width slots are embedded into the radiating patch and the ground plane to achieve triple notched bands at 3.5, 5.5, and $8.1 \mathrm{GHz}$. A parameter study is performed to examine the effect of widths and lengths of the slots on the band-notched characteristics. It indicates that the centre frequencies and the bandwidth of notched bands can be controlled by tuning the physical parameters of the slots. Frequency domain measurements including return loss, antenna transfer function, group delay, and gain of the proposed antenna have been carried out. Corresponding results demonstrate that compact UWB antennas with multiple notched bands can be obtained by using nonuniform width slots.
\end{abstract}

\section{Introduction}

Since the spectrum of $3.1-10.6 \mathrm{GHz}$ was released by the Federal Communication Commission (FCC) for commercial applications, ultrawideband (UWB) systems have attracted more and more attention, due to their merits of high data rate, low power consumption, and good immunity to multipath interference. A wide range of investigations have been done on UWB antennas which play key roles in UWB systems. Printed UWB antennas have advantages over some others owing to their low profile, conformability, and easy fabrication property [1-3].

However, UWB system design faces many challenges, the serious one of which is interference with other coexisting narrow band communication systems such as WLAN, WiMAX, and ITU X-band satellite communication systems operating in $3.3-3.7 \mathrm{GHz}, 5.15-5.825 \mathrm{GHz}$, and $8.025-$ $8.4 \mathrm{GHz}$, respectively. This problem can be overcome by using an antenna with inherent band-notched characteristic rather than adopting an extra filter which may increase the complication, area, and cost of a UWB system. A popular method to realize A band-notched function is to embed a uniform width slot into the radiation element [4-6] or the ground plane [7-9] of the UWB antennas. However, these antennas only have one or two notched bands; thus, potential interference from other narrow bands can not be filtered out. Multiple band-notched antennas have been realized by introducing multiple band-notched elements [10, 11] or a single element $[12,13]$. Nevertheless, among most antennas mentioned above, there are three issues. Firstly, in order to incorporate more band-notched elements, too much area is occupied. This does not satisfy the demand on the miniaturization of UWB systems. Secondly, due to mutual coupling among band-notched elements, the feature of each element is not independent. This increases the difficulty of UWB antenna design. Thirdly, a spurious resonance leads to a limited operating bandwidth which does not cover the whole UWB band from 3.1 to $10.6 \mathrm{GHz}$. Therefore, an effective approach should be provided to adjust the characteristic of each notched band according to a specification.

In this paper, a compact UWB antenna with triple notched bands is proposed. Instead of a uniform width slot which only creates a single notched band, a pair of nonuniform width slots are inserted symmetrically into the radiating patch to achieve dual notched bands at 3.5 and $8.1 \mathrm{GHz}$. The centre frequencies of the two notched bands can be adjusted flexibly by carefully tuning the widths and lengths of the slots. Besides, another pair of nonuniform width slots 

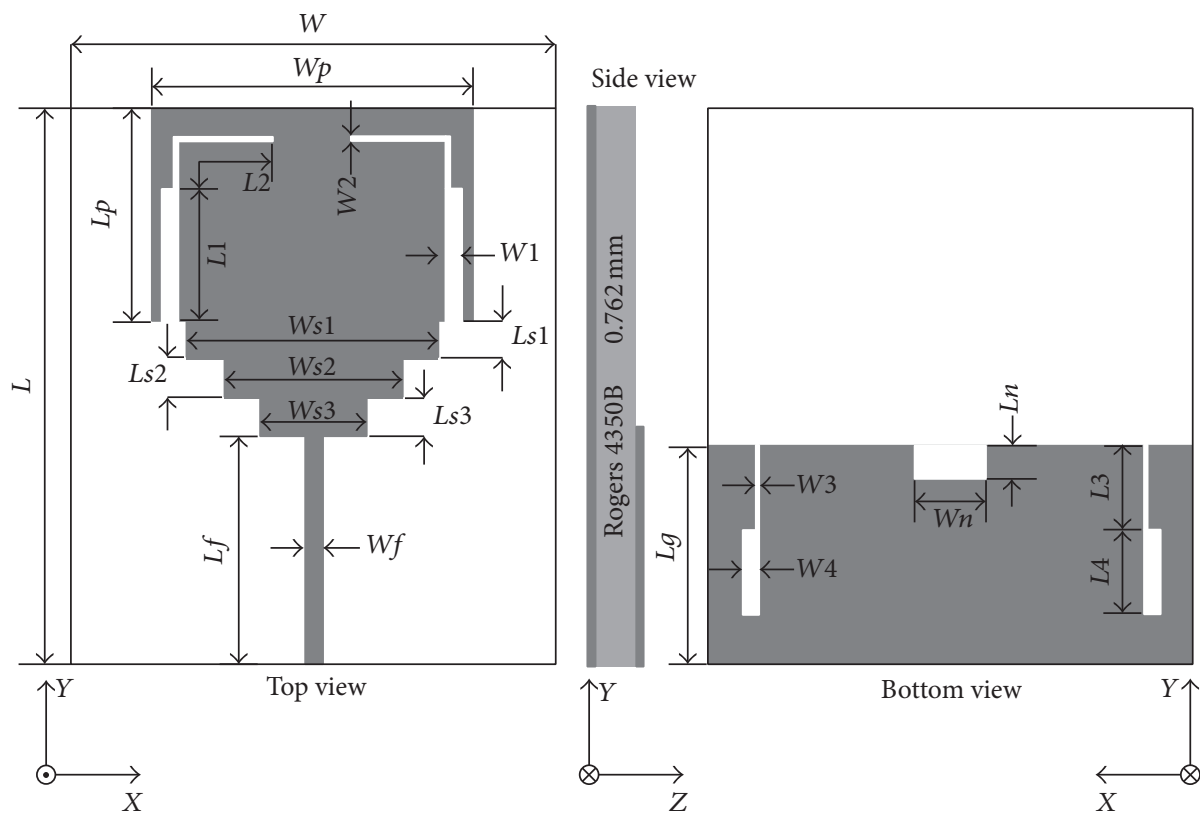

FigURE 1: Configuration of the proposed antenna.

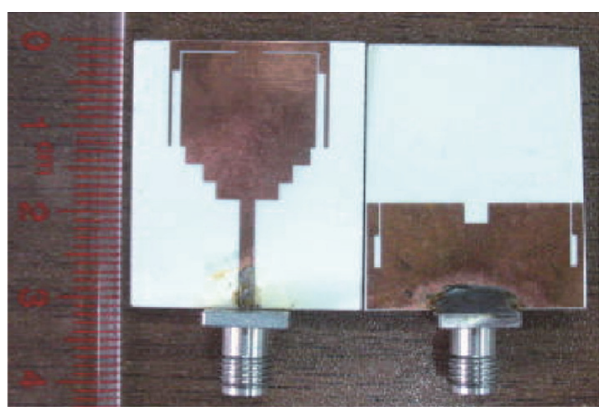

(a)

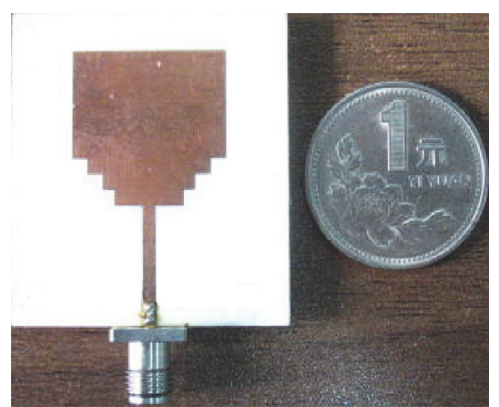

(b)

FIGURE 2: Photograph of the fabricated prototype for (a) the proposed antenna and (b) the reference antenna.

are embedded symmetrically into the ground plane to obtain a notched band at $5.5 \mathrm{GHz}$. The proposed method of using nonuniform width slot can be readily realized and retains the compact size of a UWB antenna.

\section{Antenna Configuration}

As shown in Figure 1, the proposed antenna consists of a radiating element with three staircases on the front side and a ground plane with a rectangular notch on the back side for optimum impedance matching. The patch is fed by a $50-$ $\Omega$ microstrip line of $1.67 \mathrm{~mm}$ width terminated with a SMA connector. The whole antenna is fabricated on a Rogers $4350 \mathrm{~B}$ substrate with a relative permittivity of 3.66 , a loss tangent of 0.0037 , and a thickness of $0.762 \mathrm{~mm}$. A pair of quarterwavelength nonuniform width inverted L-shaped slots are symmetrically embedded on the radiating patch to create the dual notched bands with centre frequencies of 3.5 and $8.1 \mathrm{GHz}$, while another pair of quarter-wavelength nonuniform width straight slots corresponding to the notched band centred at $5.5 \mathrm{GHz}$ are etched into the ground plane.
The optimized physical parameters of the proposed antenna are as follows: $W=25 \mathrm{~mm}, L=30.2 \mathrm{~mm}, W p=18 \mathrm{~mm}$, $L p=12 \mathrm{~mm}, W s 1=14 \mathrm{~mm}, W s 2=10 \mathrm{~mm}, W s 3=7 \mathrm{~mm}$, $L s 1=L s 2=L s 3=2 \mathrm{~mm}, W f=1.67 \mathrm{~mm}, L f=12.2 \mathrm{~mm}$, $W n=3 \mathrm{~mm}, L n=2.2 \mathrm{~mm}, L g=12 \mathrm{~mm}, W 1=1 \mathrm{~mm}$, $W 2=0.2 \mathrm{~mm}, L 1=L 2=8.5 \mathrm{~mm}, W 3=0.2 \mathrm{~mm}, W 4=$ $0.75 \mathrm{~mm}$, and $L 3=L 4=3.6 \mathrm{~mm}$. The proposed antenna is symmetrical with respect to the longitudinal direction. Moreover, a reference antenna without slots but with the same parameters was also fabricated and measured for comparison.

\section{Results and Discussion}

The proposed antenna was designed and optimized using CST Microwave Studio and a simulation cycle took about half an hour with a quad-core server. Finally, the proposed antenna and reference antenna were fabricated and measured using a vector network analyzer Agilent E5071C. Figures 2(a) and 2(b) show the photograph of the proposed and reference antenna, respectively. Both simulated and measured return loss curves for the proposed antenna are shown in Figure 3. 


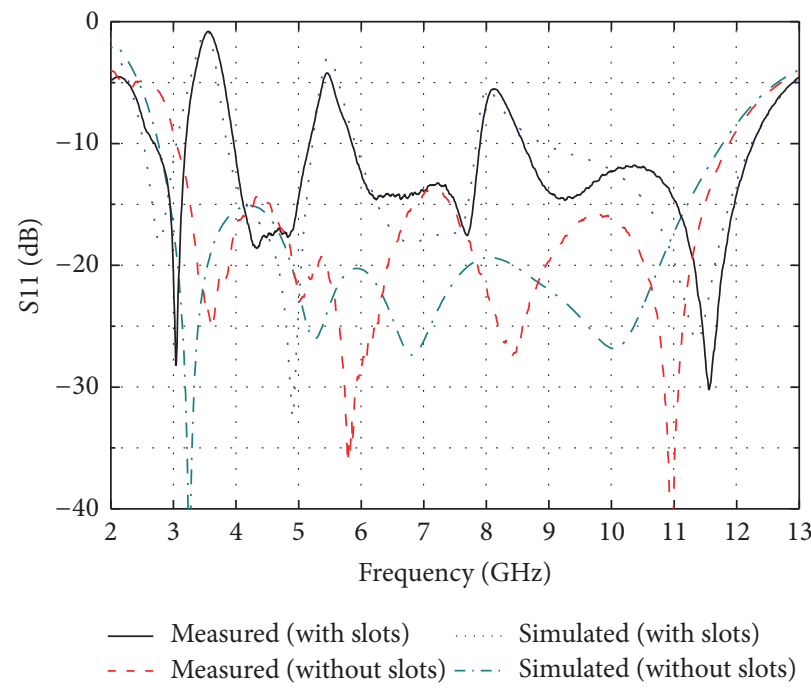

FIGURE 3: Simulated and measured return loss curves for the proposed and reference antenna.

For comparison, results of the reference antenna are also presented in Figure 3. It can be seen that the proposed antenna has an ultrawide operating band from 2.7 to $12.3 \mathrm{GHz}$ for $S 11 \leq-10 \mathrm{~dB}$, which covers the entire UWB band. Furthermore, as predicted, triple desired notched bands of 3.19-3.97 GHz, $5.16-5.85 \mathrm{GHz}$, and $7.88-8.59 \mathrm{GHz}$ for $S 11>$ $-10 \mathrm{~dB}$ are achieved. If we want to further improve the reflection coefficient, an extra resonant structure can be added which resonates at the notch frequency. In conclusion, the proposed antenna successfully avoids interference with WLAN, WiMAX, and ITU X-band satellite communication systems and retains an ultrawideband performance.

A parameter study is performed to further understand the effects of widths and lengths of the nonuniform width slots on the triple band-notched characteristics. Simulated return loss values for the proposed antenna in terms of $W 1$ and $W 2$ are shown in Figure 4(a). It is observed that as $W 1$ decreases from 1.2 to $0.6 \mathrm{~mm}$ and $W 2$ increases from 0.1 to $0.6 \mathrm{~mm}$, the nonuniform width slots on the patch convert to uniform width slots and the ratio between the first and third notched band centre frequencies increases from 2 to 3. As shown in Figure 4(b), with the increase of $L 1$ and $L 2$ from 7.5 to $9 \mathrm{~mm}$, the first and third notched band centre frequencies shift down from 3.95 to $3.29 \mathrm{GHz}$ and from 9 to $7.47 \mathrm{GHz}$, respectively, while the ratio between them is almost unchanged and maintains about 2.27. By tuning either the widths or the lengths, the first and third notched band centre frequencies can not be altered independently. However, as shown in Figure 4(c), through carefully adjusting the widths and the lengths together, the third notched band centre frequency can be changed freely with the first notched band centre frequency fixed at $3.5 \mathrm{GHz}$. Moreover, if the third notched band acts as a spurious resonance and is not desired, one can push it up away from the UWB band to maintain the UWB performance of the antenna by enlarging the ratio between $W 2$ and $W 1$. Thus, an effective approach is provided to flexibly adjust the position of the dual notched bands
TABLE 1: Various slots on the patch.

\begin{tabular}{|c|c|c|c|c|c|c|c|}
\hline \multirow{3}{*}{ Slot } & \multirow[t]{2}{*}{$W 1$} & \multirow[t]{2}{*}{$W 2$} & \multirow[t]{2}{*}{$W 2 / W 1$} & \multirow{2}{*}{$\begin{array}{l}L 1 \\
L 2\end{array}$} & \multirow[t]{2}{*}{$f_{r 1}$} & \multirow[t]{2}{*}{$f_{r 3}$} & \multirow[t]{2}{*}{$f_{r 3} / f_{r 1}$} \\
\hline & & & & & & & \\
\hline & $(\mathrm{mm})$ & $(\mathrm{mm})$ & - & $(\mathrm{mm})$ & $(\mathrm{GHz})$ & $(\mathrm{GHz})$ & - \\
\hline I & 1.2 & 0.2 & 0.17 & 8.8 & 3.5 & 7.5 & 2.1 \\
\hline II & 0.6 & 0.2 & 0.33 & 7.9 & 3.5 & 8.9 & 2.5 \\
\hline III & 0.6 & 0.6 & 1 & 7 & 3.5 & 10.5 & 3 \\
\hline IV & 0.2 & 0.6 & 3 & 6 & 3.5 & 12.1 & 3.5 \\
\hline
\end{tabular}

introduced by the nonuniform width slots or to eliminate the third notched band, if it is undesired. Relative parameters of various slots on the patch with different widths and lengths are listed in Table 1 . The effect of $L 3$ and $L 4$ on the centre frequency of the second notched band is presented in Figure 5(a). By altering $L 3$ and $L 4$ from 3.1 to $4.6 \mathrm{~mm}$, the centre frequency decreases from 6.2 to $4.4 \mathrm{GHz}$. It is worth noting that the centre frequency of the second notched band is also influenced by $W 3$ and $W 4$ significantly, as indicated in Figure 4(b). In addition, Figure 5(c) reveals that the bandwidth is also controllable by carefully tuning the length and width of the slots together. An interesting phenomenon is also found that, for the same centre frequency, larger ratio between $W 4$ and $W 3$ results in shorter slot length. As shown in Table 2, compared to an conventional uniform width slot, the length of a nonuniform width slot $(W 4 / W 3=10)$ can be reduced by $31.8 \%$. Therefore, a nonuniform width slot can be incorporated in limited space by adjusting the ratio between the widths of different segments.

In order to understand the behavior of the nonuniform width slots, especially at the triple notched bands, surface current distributions at $3.5,5.5$, and $8 \mathrm{GHz}$ are simulated and illustrated in Figures 6(a), 6(b), and 6(c), respectively. It is clear from Figure 6(b) that the surface current distribution at $5.5 \mathrm{GHz}$ is mainly concentrated on the slots embedded into the ground plane, while it is very week on the radiating patch 


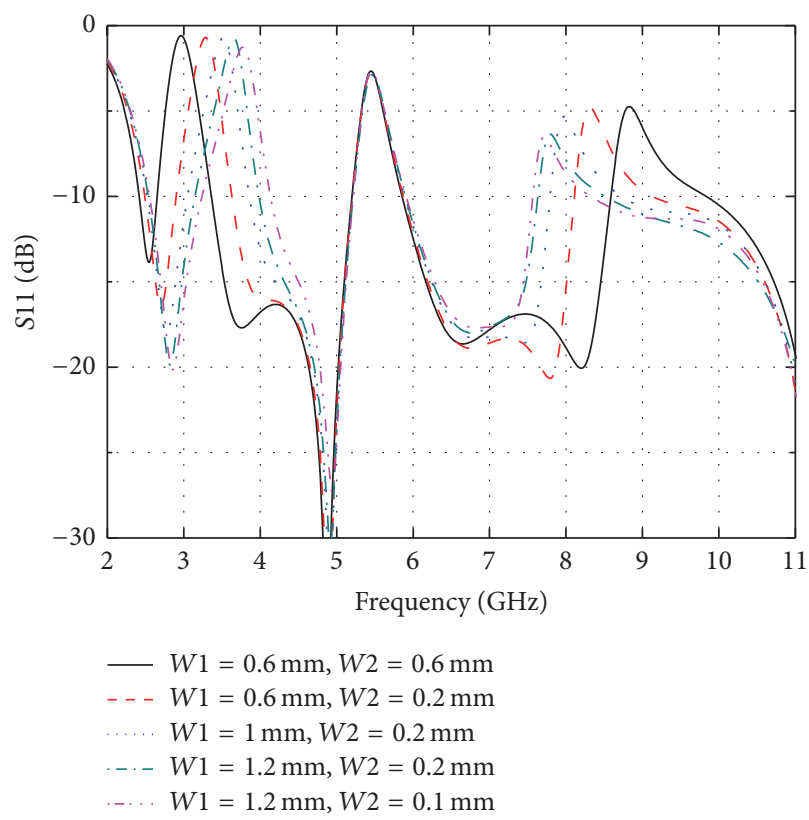

(a)

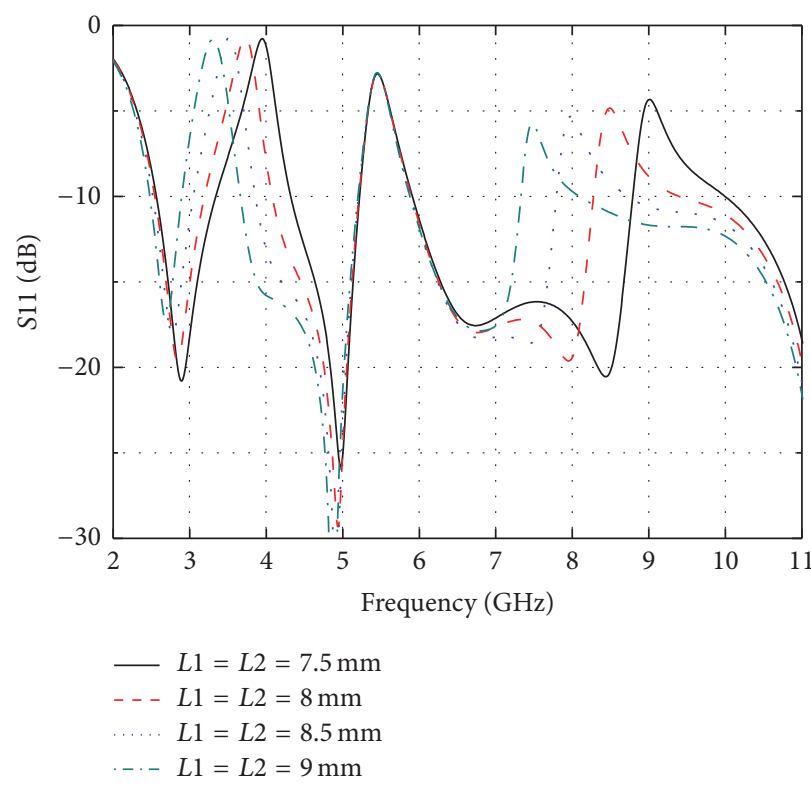

(b)

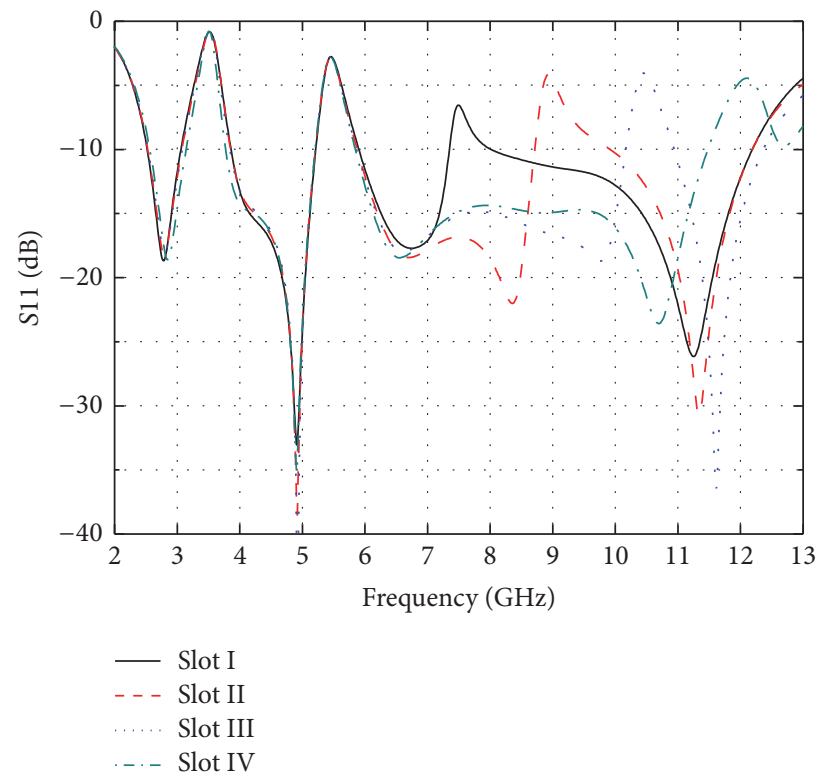

(c)

FiguRE 4: Simulated return loss values for the proposed antenna with (a) various widths (W1, W2), (b) various lengths (L1, $L 2)$, and (c) various widths and lengths (the first notched band is fixed at $3.5 \mathrm{GHz}$ ).

TABLE 2: Various slots on the ground.

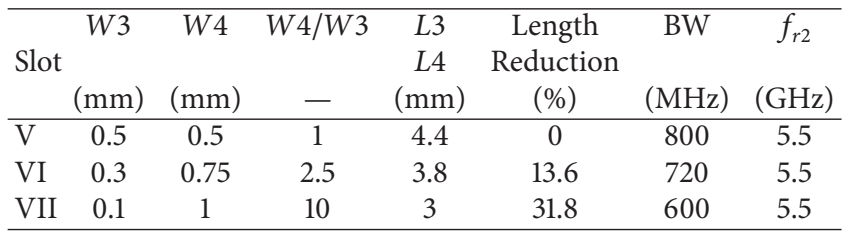

as well as the ground plane. As illustrated in Figures 6(a) and $6(\mathrm{c})$, the current at 3.5 and $8 \mathrm{GHz}$ is large on the slots inserted into the patch, while it is very small on the patch and the ground. This demonstrates that both the notched bands at 3.5 and $8 \mathrm{GHz}$ are generated by the same pair of slots on the patch. Furthermore, it can be observed from Figure 6(c) that, beside the node (Node I) at the open end of the slots on the patch, there is another node (Node II) at the turning. Accordingly, the third notched band at $8 \mathrm{GHz}$ is generated by the second-order resonance of the nonuniform width slots on the patch.

Simulated and measured radiation patterns for the proposed antenna in $X Y$ - and $Z X$-plane at 4.5 and $7 \mathrm{GHz}$ are 


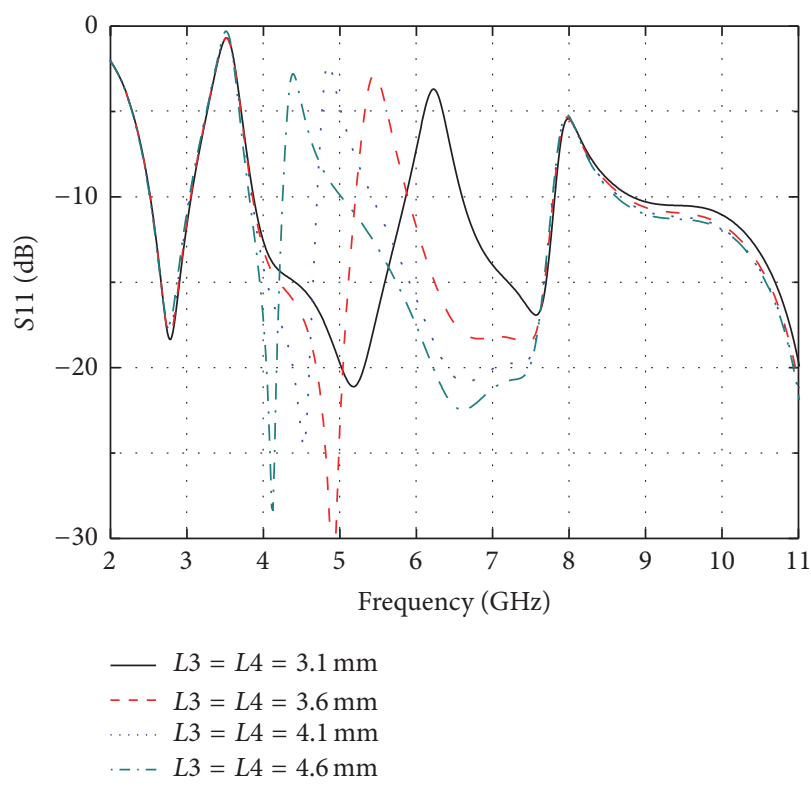

(a)

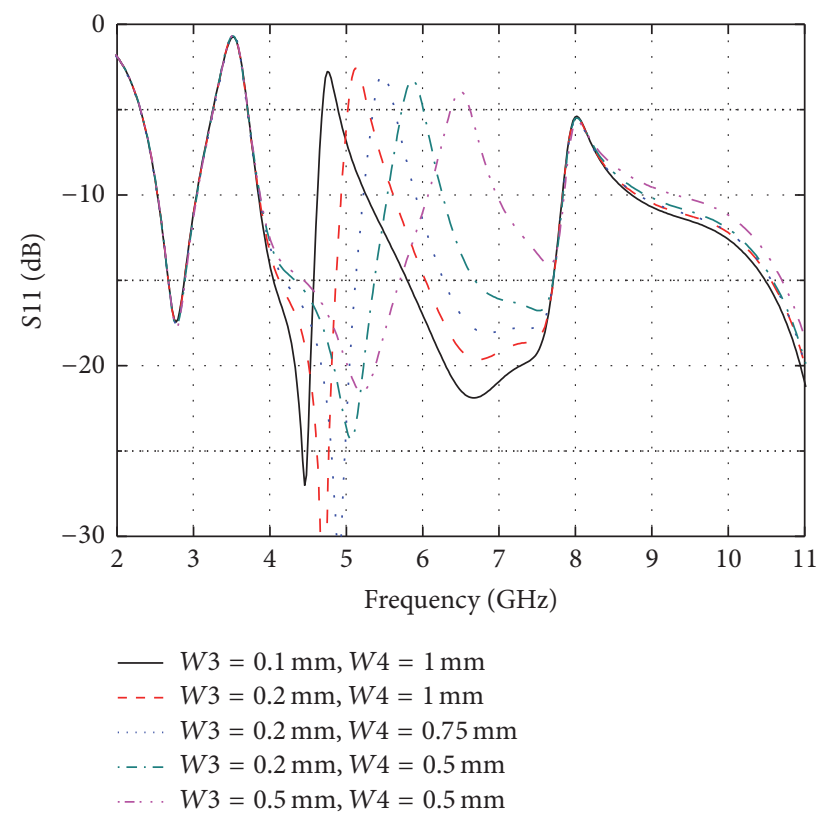

(b)

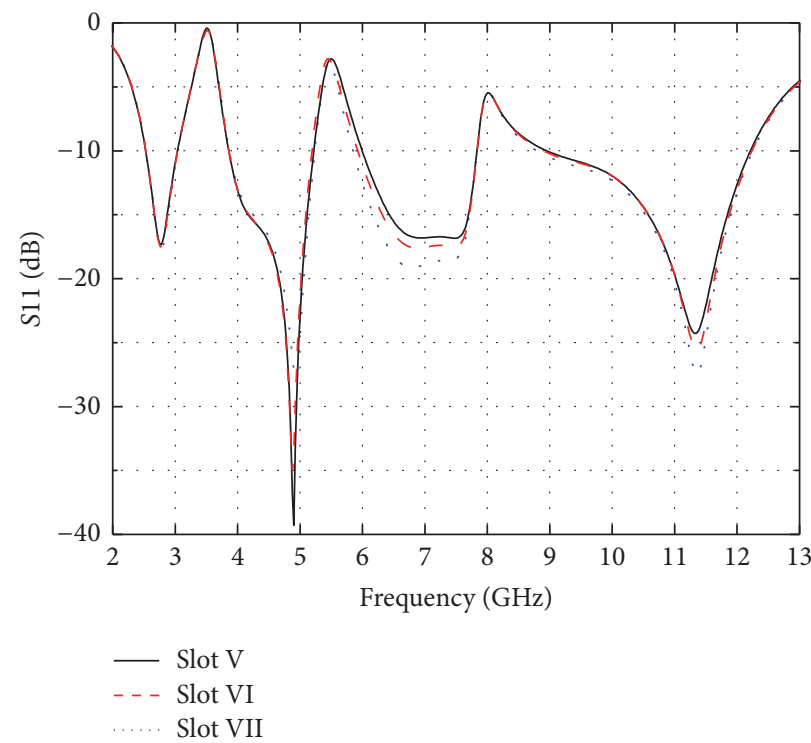

(c)

Figure 5: Simulated return loss values for the proposed antenna with (a) various widths $(W 3, W 4)$, (b) various lengths $(L 3, L 4)$, and (c) various widths and lengths (the second notched band is fixed at $5.5 \mathrm{GHz}$ ).

displayed and compared in Figures 7(a) and 7(b). The antenna has good and stable omnidirectional radiation patterns with a noncircularity less than $5 \mathrm{~dB}$ in $Z X$-plane and nearly dumbbell-shaped radiation patterns in $X Y$-plane. Transfer function and group delay were measured by using a pair of identical proposed antennas mounted on two ports of the VNA face to face with a distance of $150 \mathrm{~mm}$. The measured results are shown in Figure 8, compared with the results of reference antenna without notched bands. It can be seen that the transfer function is almost flat from 3 to $10 \mathrm{GHz}$ with a variation less than $5 \mathrm{~dB}$, while triple notched bands at 3.5 , 5.5 , and $8 \mathrm{GHz}$ with transfer gain reduction of $-30,-15$, and $-20 \mathrm{~dB}$ are observed. As shown in Figure 8, the group delay keeps constant over the entire UWB band with a fluctuation less than $1 \mathrm{~ns}$ except for variations in the notched bands. This characteristic reveals that the proposed antenna has an excellent phase linearity which results in less signal distortion [14]. Figure 9 presents the gains of both the proposed and reference antennas. As observed, sharp reduction occurs at each notched band as expected, and the maximum gain suppression is $12 \mathrm{~dB}$ at $3.5 \mathrm{GHz}$.

\section{Conclusion}

A compact printed UWB antenna has been proposed and analyzed in detail. Triple notched bands were achieved by 


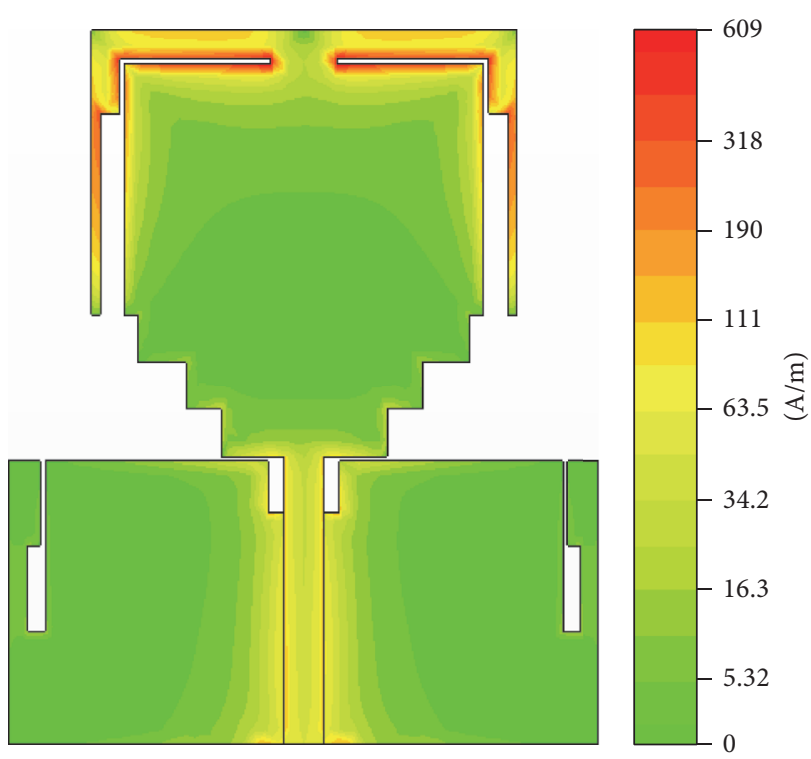

(a)

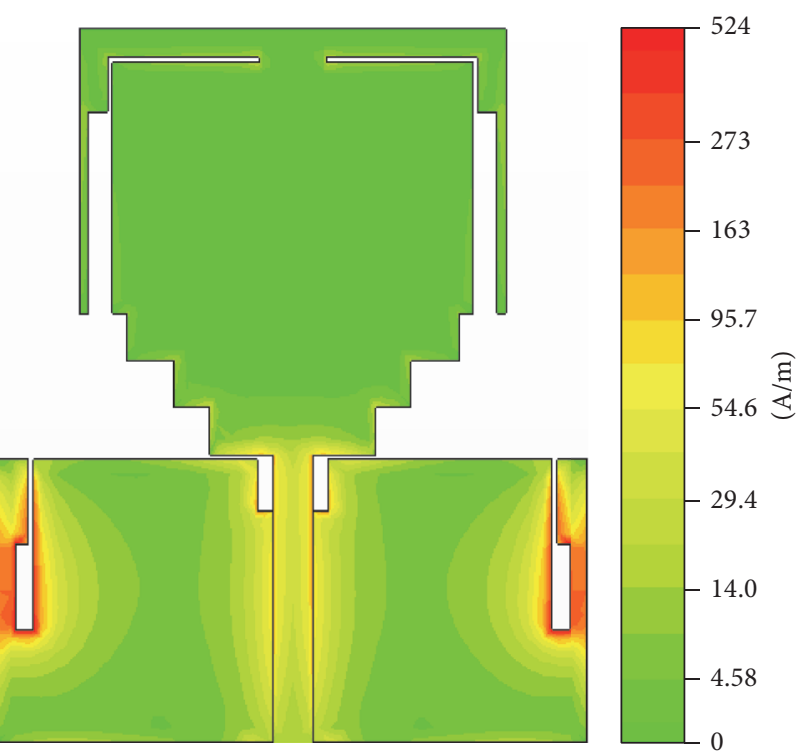

(b)

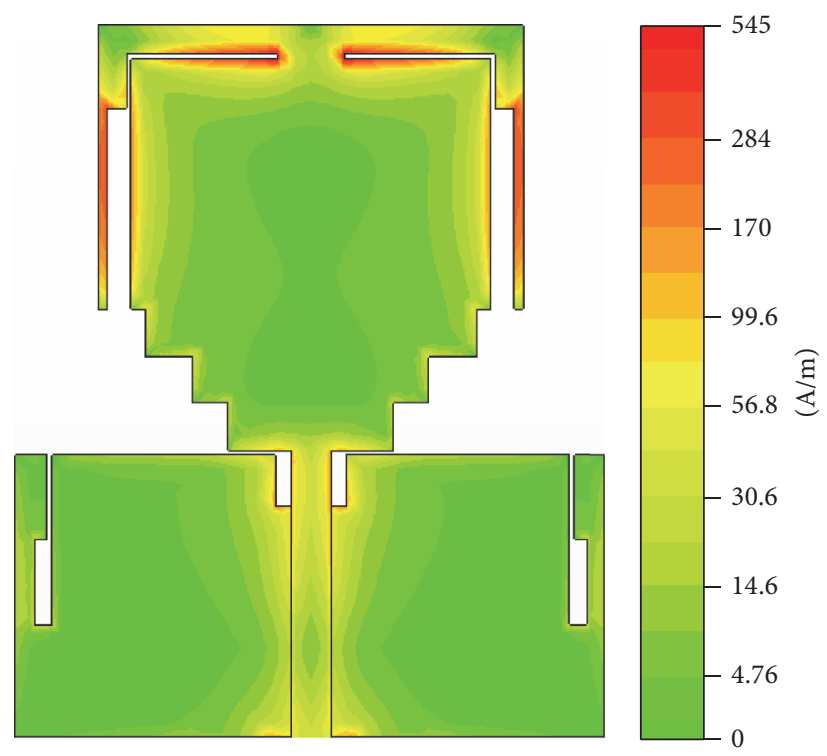

(c)

FIGURE 6: Surface current distribution at (a) $3.5 \mathrm{GHz}$, (b) $5.5 \mathrm{GHz}$, and (c) $8 \mathrm{GHz}$.

using two pairs of novel nonuniform width slots inserted into the radiating patch and the ground plane instead of conventional uniform width slots. The first and third notched bands at 3.5 and $8.1 \mathrm{GHz}$ are generated by the first and second resonance of the slots, respectively. By carefully tuning the widths and lengths of the slots together, the centre frequencies and bandwidths are controllable. Furthermore, compared to conventional uniform width slot, the entire length of nonuniform width slot can be reduced by $31.8 \%$ for the same resonant frequency. This feature is suitable for the miniaturization of UWB antenna. Therefore, the proposed antenna based on nonuniform width slots is expected for miniature UWB systems with immunity to multiple narrow bands interference or for multiband applications.

\section{Competing Interests}

The authors declare that there is no conflict of interests regarding the publication of this paper.

\section{Acknowledgments}

The authors acknowledge the support of the Key Project of National Natural Science Foundation of China (Grant 


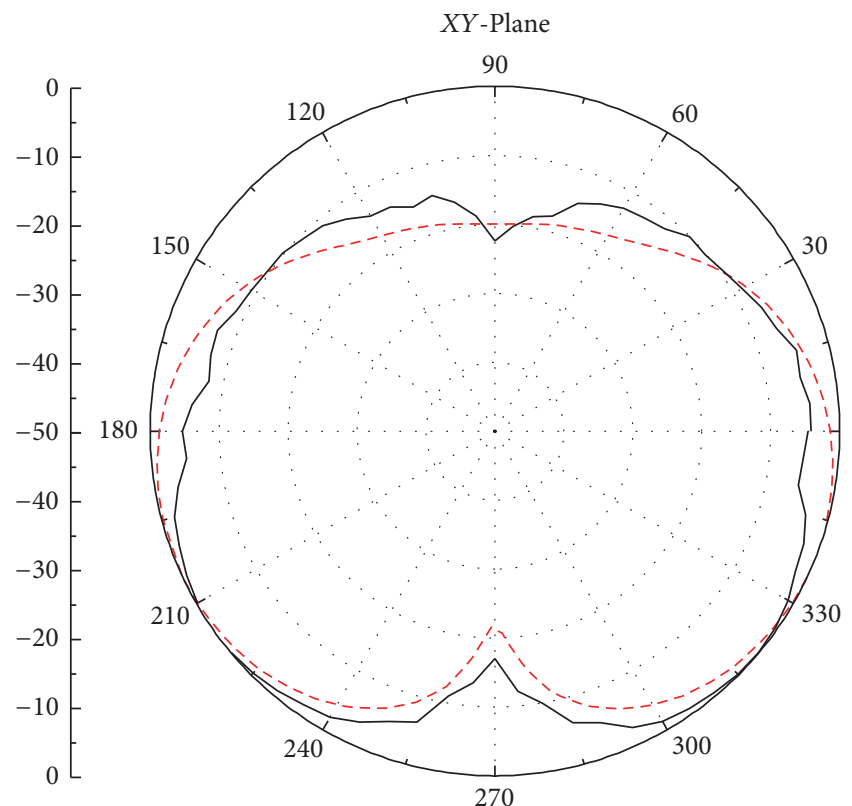

(dB)

- - - Simulated

— Measured

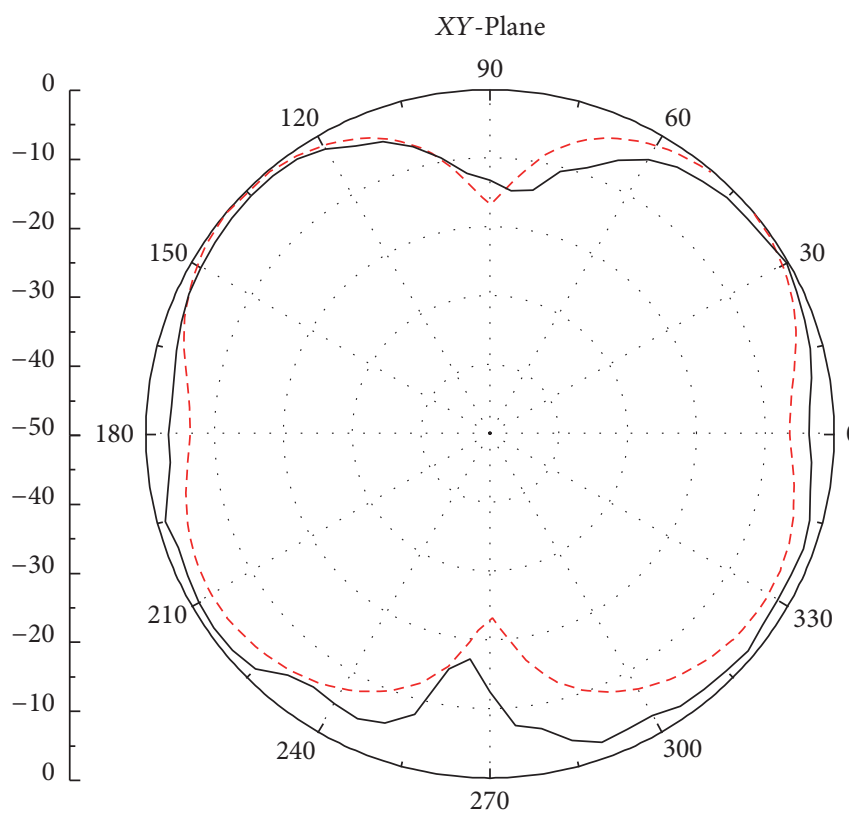

$(\mathrm{dB})$

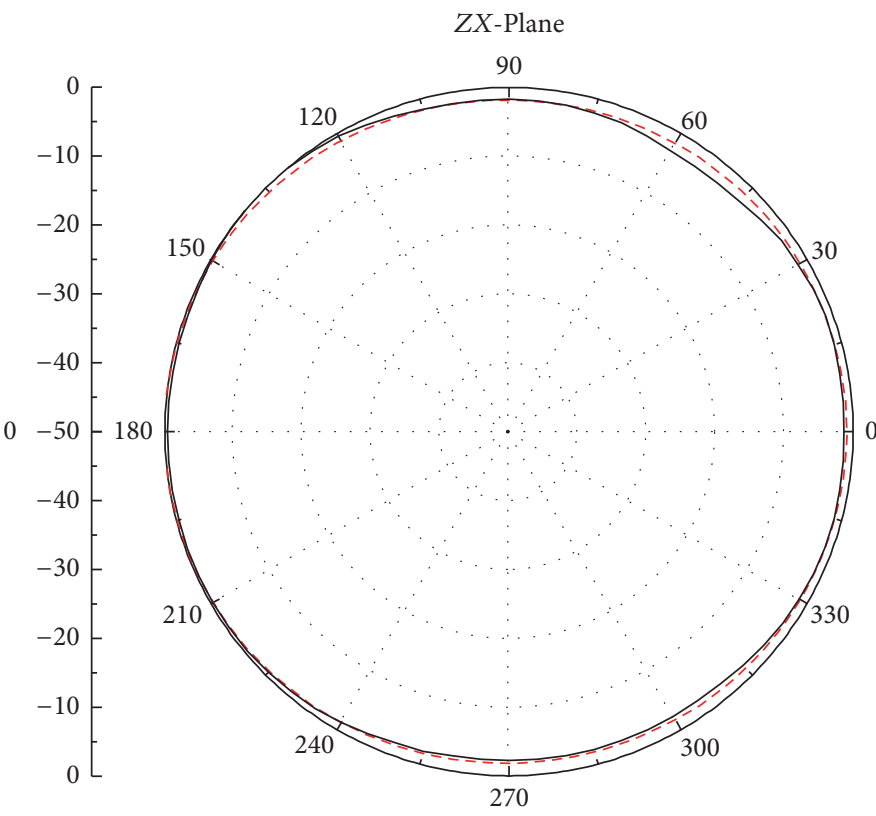

$(\mathrm{dB})$

(a)

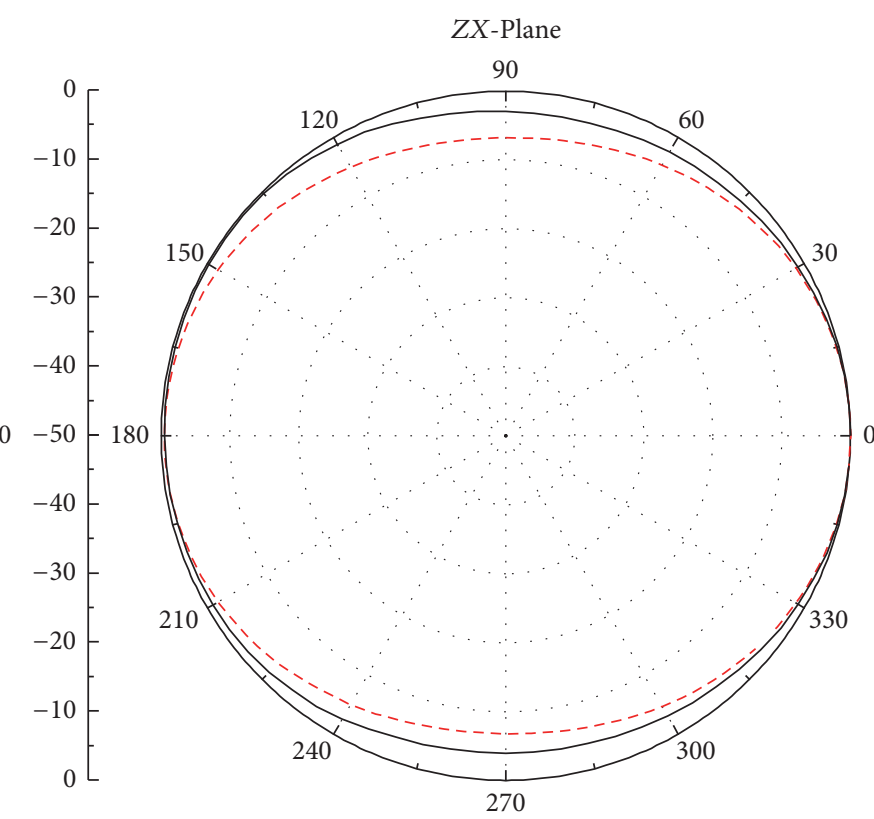

$(\mathrm{dB})$

(b)

FIGURE 7: Simulated and measured radiation patterns for the proposed antenna at (a) $4.5 \mathrm{GHz}$ and (b) $7 \mathrm{GHz}$. 


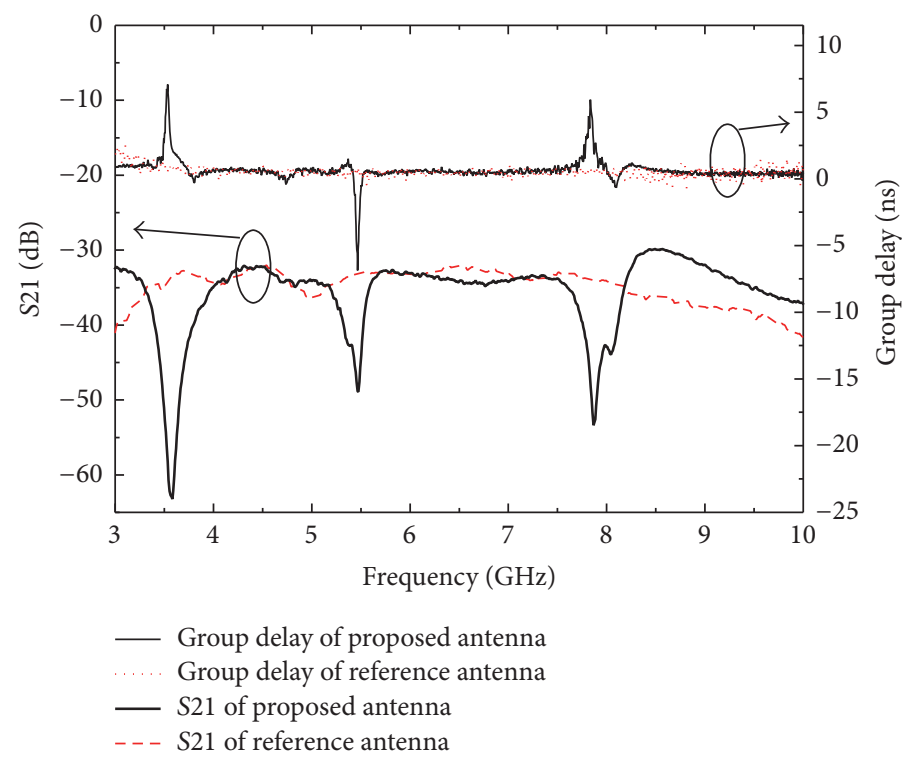

FIGURE 8: Transfer function and group delay for the proposed and reference antennas.

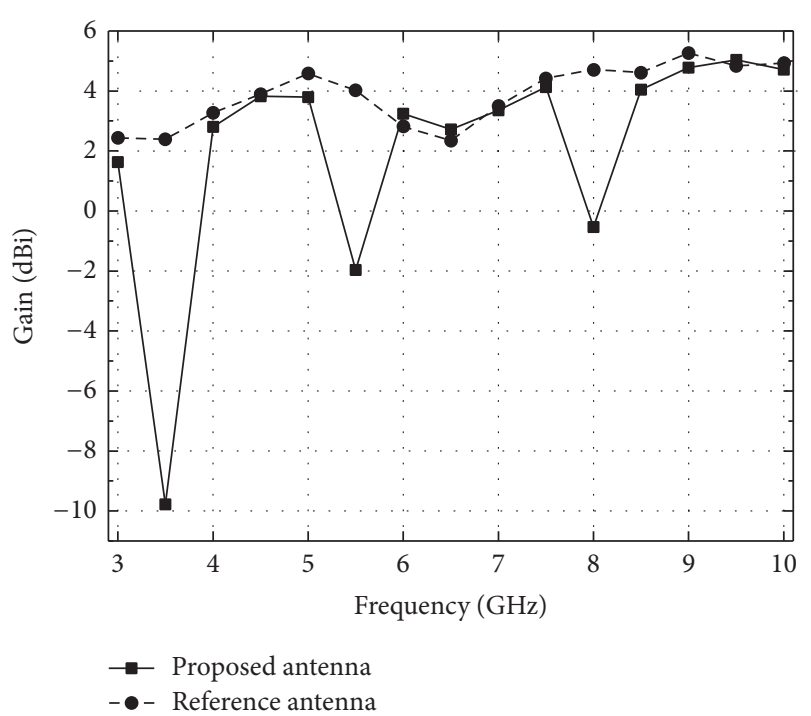

FIGURE 9: Gain for the proposed and reference antennas.

no. 51538007) and the Project of National Natural Science Foundation of China (Grant no. 71101096).

\section{References}

[1] J. Liang, C. C. Chiau, X. Chen, and C. G. Parini, "Printed circular disc monopole antenna for ultra-wideband applications," Electronics Letters, vol. 40, no. 20, pp. 1246-1248, 2004.

[2] S. H. Choi, J. K. Park, S. K. Kim, and J. Y. Park, "A new ultra-wideband antenna for UWB applications," Microwave and Optical Technology Letters, vol. 40, no. 5, pp. 399-401, 2004.

[3] C.-C. Lin, Y.-C. Kan, L.-C. Kuo, and H.-R. Chuang, "A planar triangular monopole antenna for UWB communication," IEEE Microwave and Wireless Components Letters, vol. 15, no. 10, pp. 624-626, 2005.
[4] Y. Kim and D.-H. Kwon, "CPW-fed planar ultra wideband antenna having a frequency band notch function," Electronics Letters, vol. 40, no. 7, pp. 403-405, 2004.

[5] Q.-X. Chu and Y.-Y. Yang, "A compact ultrawideband antenna with 3.4/5.5 GHz dual band-notched characteristics," IEEE Transactions on Antennas and Propagation, vol. 56, no. 12, pp. 3637-3644, 2008.

[6] K. Zhang, Y. Li, and Y. Long, "Band-notched UWB printed monopole antenna with a novel segmented circular patch," IEEE Antennas and Wireless Propagation Letters, vol. 9, pp. 1209-1212, 2010.

[7] S.-W. Su and K.-L. Wong, "Printed band-notched ultra-wideband quasi-dipole antenna," Microwave and Optical Technology Letters, vol. 48, no. 3, pp. 418-420, 2006.

[8] J. Jung, H. Lee, and Y. Lim, "Compact band-notched ultra-wideband antenna," Electronics Letters, vol. 44, no. 6, pp. 391-392, 2008.

[9] Y. D. Dong, W. Hong, Z. Q. Kuai, and J. X. Chen, "Analysis of planar ultrawideband antennas with on-ground slot bandnotched structures," IEEE Transactions on Antennas and Propagation, vol. 57, no. 7, pp. 1886-1893, 2009.

[10] Y. Zhang, W. Hong, C. Yu, Z.-Q. Kuai, Y.-D. Don, and J.-Y. Zhou, "Planar ultrawideband antennas with multiple notched bands based on etched slots on the patch and/or split ring resonators on the feed line," IEEE Transactions on Antennas and Propagation, vol. 56, no. 9, pp. 3063-3068, 2008.

[11] N. Mohammadian, M.-N. Azarmanesh, and S. Soltani, "Compact ultra-wideband slot antenna fed by coplanar waveguide and microstrip line with triple-band-notched frequency function," IET Microwaves, Antennas and Propagation, vol. 4, no. 11, pp. 1811-1817, 2010.

[12] Y. D. Dong, W. Hong, Z. Q. Kuai et al., "Development of ultrawideband antenna with multiple band-notched characteristics using half mode substrate integrated waveguide cavity technology," IEEE Transactions on Antennas and Propagation, vol. 56, no. 9, pp. 2894-2902, 2008.

[13] Y. Zhang, W. Hong, C. Yu, J.-Y. Zhou, and Z.-Q. Kuai, "Design and implementation of planar ultra-wideband antennas with 
multiple notched bands based on stepped impedance resonators," IET Microwaves, Antennas and Propagation, vol. 3, no. 7, pp. 1051-1059, 2009.

[14] Y. J. Cho, K. H. Kim, D. H. Choi, S. S. Lee, and S.-O. Park, "A miniature UWB planar monopole antenna with $5-\mathrm{GHz}$ band-rejection filter and the time-domain characteristics," IEEE Transactions on Antennas and Propagation, vol. 54, no. 5, pp. 1453-1460, 2006. 


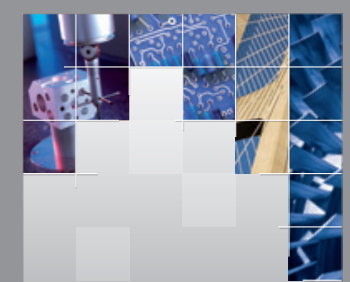

\section{Enfincering}
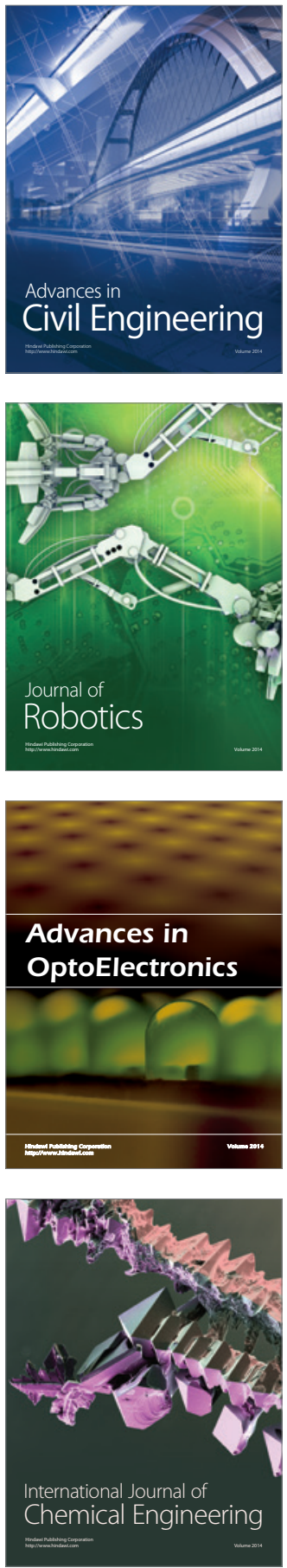

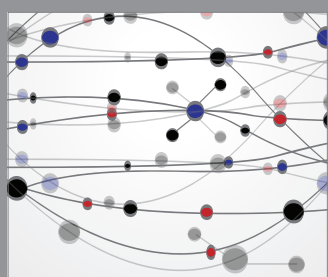

The Scientific World Journal

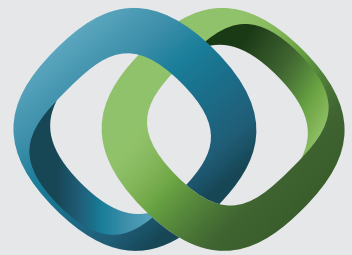

\section{Hindawi}

Submit your manuscripts at

https://www.hindawi.com
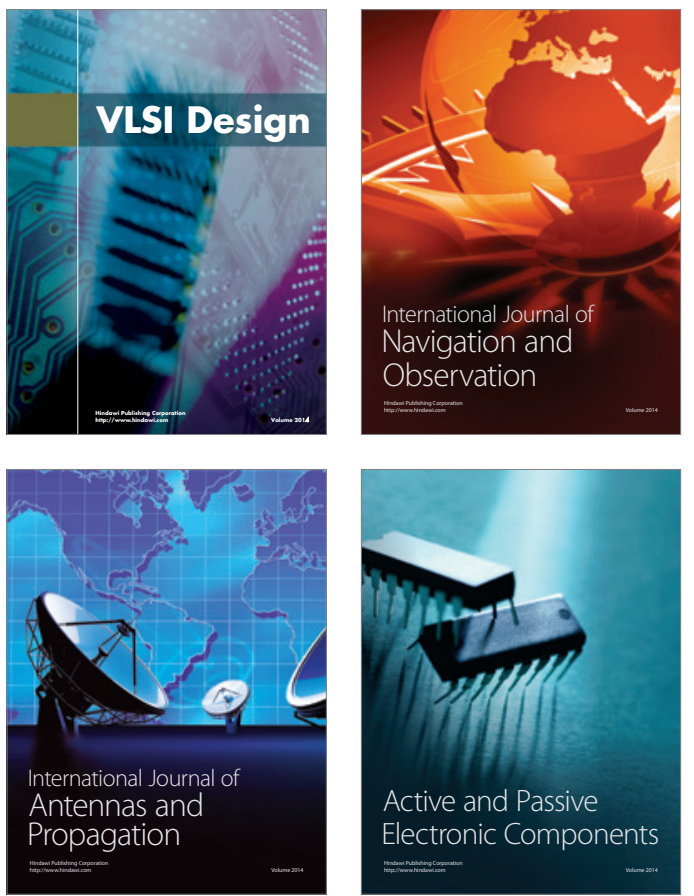
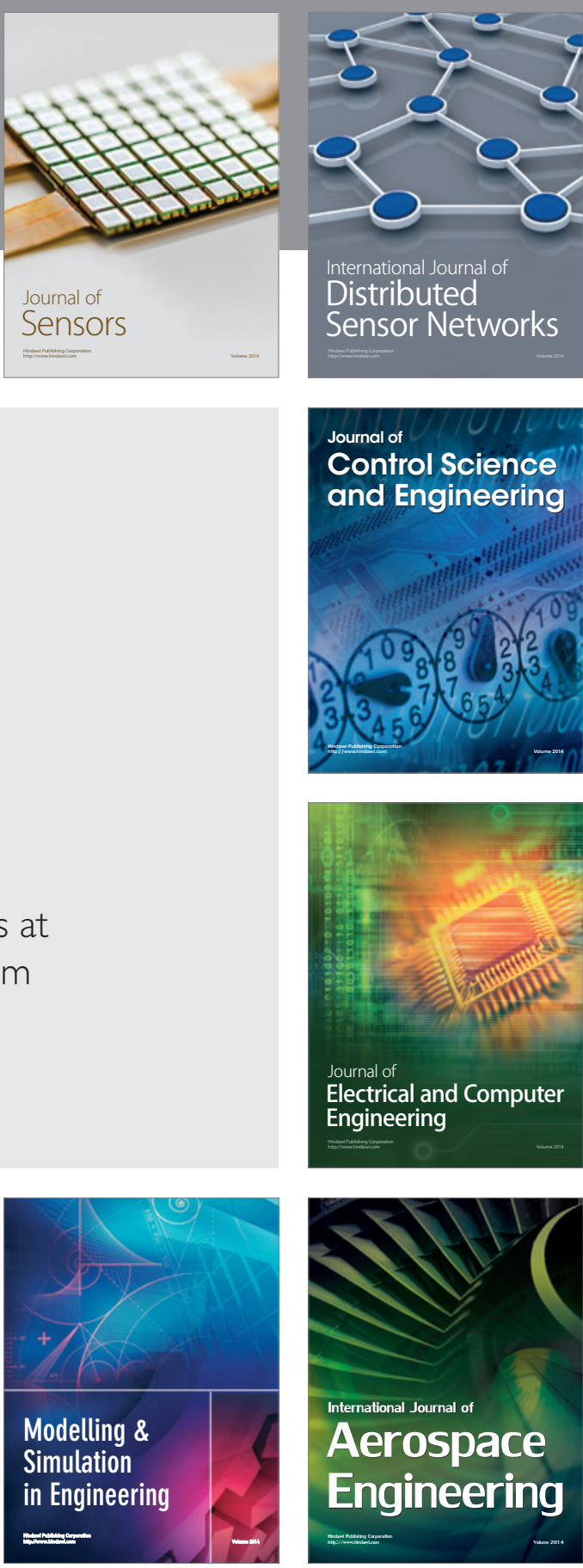

International Journal of

Distributed

Sensor Networks

$-$

Joumal of

Control Science

and Engineering
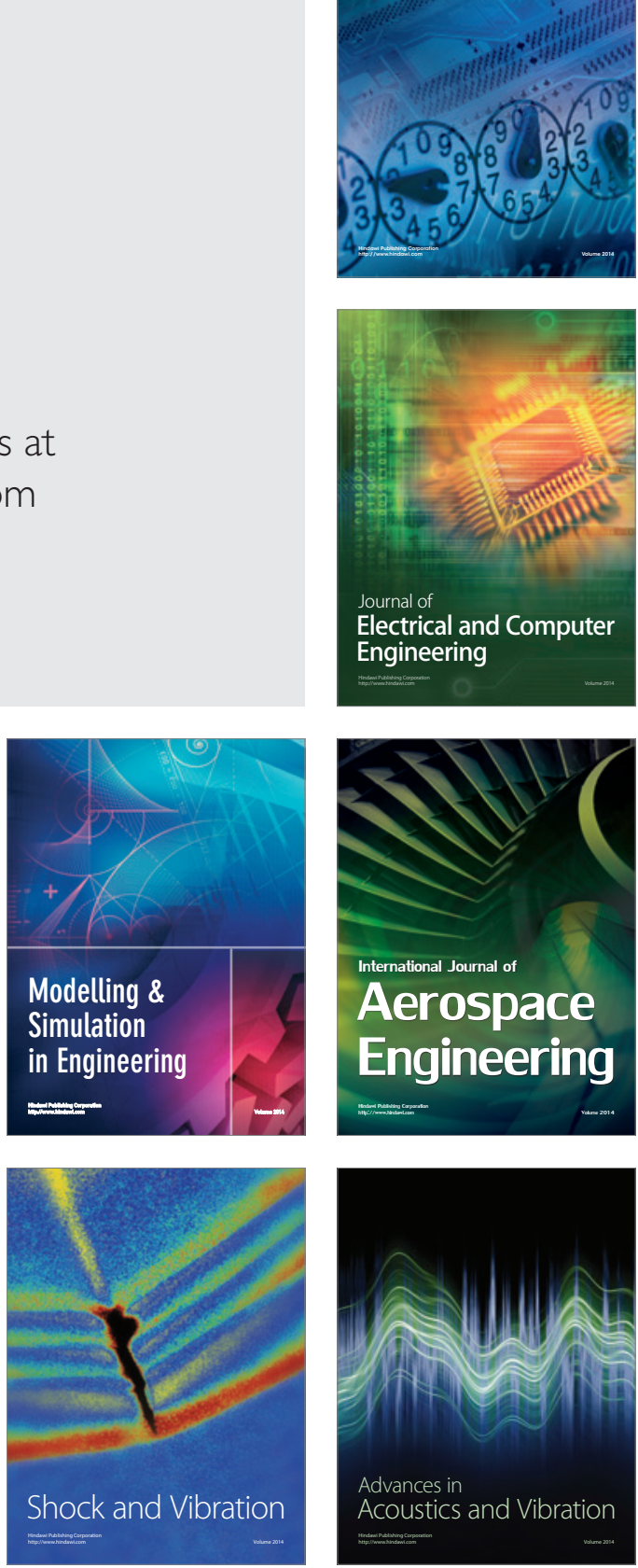